\title{
Neonatal Administration of Thimerosal Causes Persistent Changes in Mu Opioid Receptors in the Rat Brain
}

\author{
Mieszko Olczak • Michalina Duszczyk • \\ Pawel Mierzejewski · Teresa Bobrowicz • \\ Maria Dorota Majewska
}

Accepted: 12 August 2010/Published online: 28 August 2010

(C) The Author(s) 2010. This article is published with open access at Springerlink.com

\begin{abstract}
Thimerosal added to some pediatric vaccines is suspected in pathogenesis of several neurodevelopmental disorders. Our previous study showed that thimerosal administered to suckling rats causes persistent, endogenous opioid-mediated hypoalgesia. Here we examined, using immunohistochemical staining technique, the density of $\mu$-opioid receptors (MORs) in the brains of rats, which in the second postnatal week received four i.m. injections of thimerosal at doses $12,240,1,440$ or $3,000 \mu \mathrm{g} \mathrm{Hg} / \mathrm{kg}$. The periaqueductal gray, caudate putamen and hippocampus were examined. Thimerosal administration caused dosedependent statistically significant increase in MOR densities in the periaqueductal gray and caudate putamen, but decrease in the dentate gyrus, where it was accompanied by the presence of degenerating neurons and loss of synaptic vesicle marker (synaptophysin). These data document that exposure to thimerosal during early postnatal life produces
\end{abstract}

M. Olczak · M. Duszczyk · P. Mierzejewski ·

M. D. Majewska ( $\square)$

Department of Pharmacology and Physiology of the Nervous

System, Institute of Psychiatry and Neurology,

Sobieskiego 9 str., 02-957 Warsaw, Poland

e-mail: majewska@ipin.edu.pl

M. Olczak

Department of Forensic Medicine, Medical University

of Warsaw, Oczki 1 str., 02-007 Warsaw, Poland

T. Bobrowicz

Department of Neuropathology, Institute of Psychiatry

and Neurology, 02-957 Warsaw, Poland

M. D. Majewska

Department of Biology and Environmental Science,

University of Cardinal Stefan Wyszynski,

Wóycickiego Str. 1/3, 01-815 Warsaw, Poland lasting alterations in the densities of brain opioid receptors along with other neuropathological changes, which may disturb brain development.

Keywords Thimerosal - Mu opioid receptors - Rat . Brain · Development

\section{Introduction}

Thimerosal (THIM), an organomercury compound, which contains approximately $49 \%$ mercury $(\mathrm{Hg}$ ) by weight, has been used for decades as a preservative in pediatric vaccines without adequate testing for its safety in developing organisms. THIM is metabolized in the body first into ethylmercury and subsequently into other organic and inorganic mercury forms [1]. Centuries of human experience and a large body of scientific data document that all forms of $\mathrm{Hg}$ are highly toxic. Considerable amounts of $\mathrm{Hg}$ have been found in the blood of human infants after the injection of THIM-containing vaccines [2,3] and studies conducted with infant monkeys showed that $\mathrm{Hg}$ from THIM-vaccine injections accumulates in the brain at concentrations many times higher than those in the blood, and that it stays there for months or years [4]. Post vaccination levels of $\mathrm{Hg}$ in infant brains may reach medium nanomolar concentrations, which are neurotoxic and kill neurons in vitro [5]. THIM doses equivalent to those used in vaccines have been shown to harm the brains of developing mice [6].

Early life exposure to mercurials, including THIM, is suspected to be a pathogenic factor in several neurodevelopmental disorders [7-10]. We have previously shown that THIM administration to suckling rats in a mode similar to infant immunization and at doses analogous to those used in pediatric vaccines, or higher, persistently augments 
the activity of endogenous opioid system in adult animals, manifested by hypoalgesia (blocked by naloxone) and enhanced sensitivity to morphine [11]. The precise neurochemical mechanism of this effect is unknown at present, but could be complex. It may be due to increased production of endogenous or food-derived opioids, their decreased degradation, an amplified expression of $\mu$ opioid receptors (MORs), or to other factors. Possible involvement of opioid receptors in the hypoalgesic effect of THIM is suggested by the study of Zanoli et al. [12], which showed that administration of methylmercury to pregnant rats augmented the density of MORs in the brains of their offspring. Methylmercury is pharmacodynamically very similar to ethylmercury, although it somewhat differs from it in pharmacokinetics $[1,4,13]$.

The present study is a follow-up of our earlier research. Here we examined, using immunohistochemical technique, the density of MORs in the brains of young adult rats, which in early postnatal life were treated with different doses of THIM. We concentrated on analysis of the brain regions rich in opioid receptors, such as the periaqueductal gray (PAG), the caudate putamen (CPU) and the hippocampus $[14,15]$.

\section{Experimental Procedures}

\section{Animals and Drug Administration}

Pregnant Wistar rats were supplied by a breeder (Medical Research Centre, Polish Academy of Sciences, Warsaw, Poland). The animals were kept in a room under standard environmental conditions until breeding $\left(22 \pm 1^{\circ} \mathrm{C}\right.$, a relative humidity of $60 \%$, a $12 \mathrm{~h}-12 \mathrm{~h}$ light-dark cycle with lights on at 07:00 h). Standard laboratory chow (Labofeed H, WPIK, Kcynia, Poland) and tap water were available ad libitum. All experiments were conducted according to the ethical standards laid down in respective Polish and European (directive No. 86/609/EEC) regulations. All procedures were reviewed and approved by the local ethics committee on animal studies.

THIM from Sigma-Aldrich, Poland, was used in the experiments. The Hg content in THIM substance was analyzed by the accredited Chemical Laboratory of MultiElemental Analyses at Wroclaw University of Technology by the method of atomic absorption spectroscopy. According to their analysis, the $\mathrm{Hg}$ content in THIM was $48 \%$. THIM dissolved in saline was injected into newborn rats on the postnatal days 7, 9, 11 and 15 in four equal doses $(12-3,000 \mu \mathrm{g} \mathrm{Hg} / \mathrm{kg})$ in a volume of $50 \mu \mathrm{l}$, i.m. into glutei maximi, as described before [11], according to the method of Hornig et al. [6]. The lowest dose used $(12 \mu \mathrm{g} \mathrm{Hg} / \mathrm{kg})$ is in the order of THIM doses still present in infant vaccines in many countries [11]. Analogous doses were used in studies in developing mice and monkeys by other investigators [4, 6]. Control rats received saline injections following the same scheme. Rats from one litter received the same treatment. There were 4-7 litters per dose-treatment. Each animal was weighed before THIM injection, and the amount of the drug given was adjusted to its weight. Weights of rats at the time of drug injections on postnatal days 7,9,11 and 15 were, respectively: $13.5 \pm 1.7,16.5 \pm 1.7,21.3 \pm 2.2$, $28+2.1 \mathrm{~g}$ (average \pm SEM; $N=124$ ). Pups were weaned on the 28th postnatal day and on that day were separated into male and female cages.

\section{Brain Acquisition}

On the 20th postnatal week, the animals were euthanized by pentobarbital overdosing (Biowet Puławy, Poland), and then decapitated. The rats treated with two higher doses of THIM $(1,440$ and $3,000 \mu \mathrm{g} \mathrm{Hg} / \mathrm{kg})$ were from the original litters, which were used for different behavioral and pathological tests [11], but were experimentally naïve. A separate group of experimentally naïve rats, treated with two lower doses of THIM, 12 and $240 \mu \mathrm{g} \mathrm{Hg} / \mathrm{kg}$ (4 litters per each drug-treatment) was sacrificed on the 8th postnatal week according to the same procedure. Each experimental group was composed of 5 animals, with 2 at the most coming from the same litter. Only males were used in the present study.

The brains were removed within $30 \mathrm{~s}$ after decapitation and placed into a buffered formaldehyde solution for $24 \mathrm{~h}$. After that they were passed through ethanol solutions of increasing concentrations (60-100\%) and xylene, finishing with paraffin. The paraffin blocks were stored in a refrigerator at $3^{\circ} \mathrm{C}$ until the slicing. The brains were sliced using a microtome, and the sections were gently placed on basic microscope glasses covered previously with L-silane. The section thickness was 4 microns. The sliced tissue was placed in an incubator set at $56^{\circ} \mathrm{C}$ for $3 \mathrm{~h}$.

\section{H.E. Staining}

To evaluate gross tissue pathology, the corresponding specimens showing hippocampus (Bregma -3.84) [16] were sequentially executed through following stages: xylene, ethanol, water, then with hematoxylin (5 min), rinsed with water $(10 \mathrm{~min})$ treated with eosin $(1 \mathrm{~min})$, rinsed with water ( $2 \mathrm{~min})$, then washed with ethanol and xylene, finally immersed with Histofluid using cover glasses.

Immunohistochemistry and Receptor Density Counting

The specimens were stained using Rabbit Anti-Mu Opioid Receptor Monoclonal Antibody Clone EP1470Y (1:100) (from Abcam, USA) and R.T.U. Vectastain Kit (from 
Vector Laboratories, USA), and then treated with: diaminobenzidine and hydrogen peroxide solution $(1 \mathrm{ml}$ DAB $+1 \mathrm{ml}$ TRIS-EDTA solution $+1.6 \mu \mathrm{l} 30 \%$ hydrogen peroxide; $3 \mathrm{~min}$ ), ethanol, xylene, finally immersed in Histofluid (Marienfeld) using cover glasses. The microphotographs of the brain sections were made with the Olympus BX41 microscope and Olympus DP25 digital camera. The images were saved in TIFF format. For each experiment microphotographs were made with the same light level for all sections.

To evaluate MOR density, the following sections were used for analysis: (1) sections showing the periaqueductal gray (PAG) (Bregma -6.36) included regions: the dorsomedial periaqueductal gray (DMPAG) and the lateral periaqueductal gray (LPAG); (2) sections showing the caudate putamen (Bregma -1.20) were analyzed in the North-East quadrant; (3) sections showing the hippocampus (Bregma $-3.60)$ were used to analyze the dentate gyrus. The position of the regions was determined according to the rat brain atlas [16]. For analysis of receptor density, microphotographs of each region were taken with a magnification of $400 \times$ (area of $35452.23 \mu \mathrm{m}^{2}$ ). The MOR density was counted as an area fraction in the analyzed region, with ImageJ 1,41o software and used for statistical analysis. The area fraction was automatically counted with a "threshold" function of the ImageJ program, which marks all the pixels of chosen gray value and counts all the groups of marked pixels (stained receptors) within the selected area [17].

\section{Synaptophysin Reaction}

Synaptophysin immunoreactivity was uses as a marker of synaptic density. The specimens were stained using Synaptophysin Lyophilized Mouse Monoclonal Antibody (Novocastra). They were executed through following stages: deparaffination (xylene, ethanol, water), antigens uncovering by heating (microwave, $15 \mathrm{~min}, 1,200 \mathrm{~W}$ ) in citrate buffer ( $0.01 \mathrm{M}, \mathrm{pH} 6.0)$, methanol and $3 \%$ hydrogen peroxide solution (20 min), TRIS-saline (15 min, $\mathrm{pH} 7.6$ ), serum swine (60 min) (Daco, Poland), primary antibody Synaptophysin Lyophilized Mouse Monoclonal Antibody (1:100, over night) (Millipore), TRIS-saline (15 min, pH 7.6), secondary antibody JgG Mouse (1:200, $45 \mathrm{~min}$ ) (Sigma, Poland), TRIS-saline (15 min, pH 7.6), streptavidine (1:500, $60 \mathrm{~min})$ (Sigma), TRIS-saline (15 min, $\mathrm{pH}$ 7.6), diaminobenzidine and hydrogen peroxide solution (3 min), ethanol, xylene, and finally immersed with Histofluid using cover glasses.

\section{Synaptic Density Counting}

To assess the synaptic density, sections showing synaptophysin reaction in the hippocampus (CA3 field) were analyzed. Positions of the regions were determined according to the rat brain atlas (around Bregma $-3.84 \mathrm{~mm}$ ). Microphotographs of each region were taken from both cerebral hemispheres with magnification of 200 (area $141808.92 \mu \mathrm{m}^{2}$ ). The synaptic density (stained synapses) was counted in a manner similar to counting MORs with ImageJ 1,41o software. Two corresponding areas from opposite hemispheres per animal per structure were analyzed. The synaptic density from each side and structure was averaged for each animal and used for statistical analysis.

\section{Statistical Analysis}

The STATISTICA software package for Windows (StatSoft, Tulsa, OK, USA) was used to analyze all data. An analysis of variance (ANOVA) was used to compare experimental groups. An LSD test was employed for individual post-hoc comparisons. Probability $(P)$ levels less than 0.05 was considered significant.

\section{Results}

Results presented in Fig. 1 and Tables 1, 2 and 3 show that early postnatal THIM administration changes MOR density in several brain regions of adult rats $(N=5$ per experimental group). Figure 1 illustrates examples of photographs of the analyzed brain regions. The brains of control animals and those that received four injections of lower doses of THIM (12 and $240 \mu \mathrm{g} \mathrm{Hg} / \mathrm{kg}$ ), were examined on the 8th postnatal week for MOR density in the PAG region. The THIM administration increased MOR density in the PAG in a dose-dependent manner (Table 1). One way ANOVA (Hg dose) revealed statistically significant effect of dose $[F(2,6)=8.087 ; P=0.019]$ in the dorsomedial periaqueductal gray (DMPAG). The post-hoc analysis confirmed a significant effect at dose $240 \mu \mathrm{g} \mathrm{Hg} / \mathrm{kg}(P=0.007)$. In the lateral periaqueductal gray (LPAG) a similar trend was observed, even though one way ANOVA revealed a nonsignificant effect of $\mathrm{Hg}$ dose $[F(2,8)=3.514 ; P=0.08]$.

The brains of the control rats and those treated with higher doses of THIM $(1,440$ and $3,000 \mu \mathrm{g} \mathrm{Hg} / \mathrm{kg})$ were assessed for MOR density on the 20th postnatal week ( $N=5$ per experimental group). The PAG region, caudate putamen (CPU) and dentate gyrus (DG) were examined. Treatment with both doses of THIM statistically significantly increased MOR density in the DMPAG and LPAG regions (Table 2). For the DMPAG, one way ANOVA revealed statistically significant effect of dose $[F(2,12)=$ 13.757; $P<0.001]$. The post-hoc analysis confirmed a significant effects at the doses $1,440 \mu \mathrm{g} \mathrm{Hg} / \mathrm{kg}(P<0.001)$ and $3,000 \mu \mathrm{g} \mathrm{Hg} / \mathrm{kg}(P=0.009)$. For the LPAG, one way 
Fig. 1 Changes in MOR density in different brain structures of neonatally THIMtreated rats. Images are representative photographs of MOR reaction, visualized as brown/dark rings around cells (pointed with arrows). THIM administration led to increase of MOR density in the PAG

(a-d) and the CPU

$(\mathbf{g}-\mathbf{h})$ (increase pointed with black arrows), but to decrease of MOR density in the DG (e-f) (decrease pointed with white arrows). a DMPAG, control, 8-week, $\times 400$; b DMPAG, $240 \mu \mathrm{g} \mathrm{Hg} / \mathrm{kg}$, 8-week, $\times 400$; c DMPAG, control, 20-week, $\times 400$; d DMPAG, 3,000 $\mu \mathrm{g} \mathrm{Hg} / \mathrm{kg}$, 20-week, $\times 400$; e DG, control, 20-week, $\times 100$; f DG, 3,000 $\mu \mathrm{g}$ $\mathrm{Hg} / \mathrm{kg}, 20$-week, $\times 100 ;$ g CPU, Control, 20-week, $\times 400$;

h CPU, $3,000 \mu \mathrm{g} \mathrm{Hg} / \mathrm{kg}$,

20-week, $\times 400$. For interpretation of the references to color in this figure legend, the reader is referred to the online version of this article

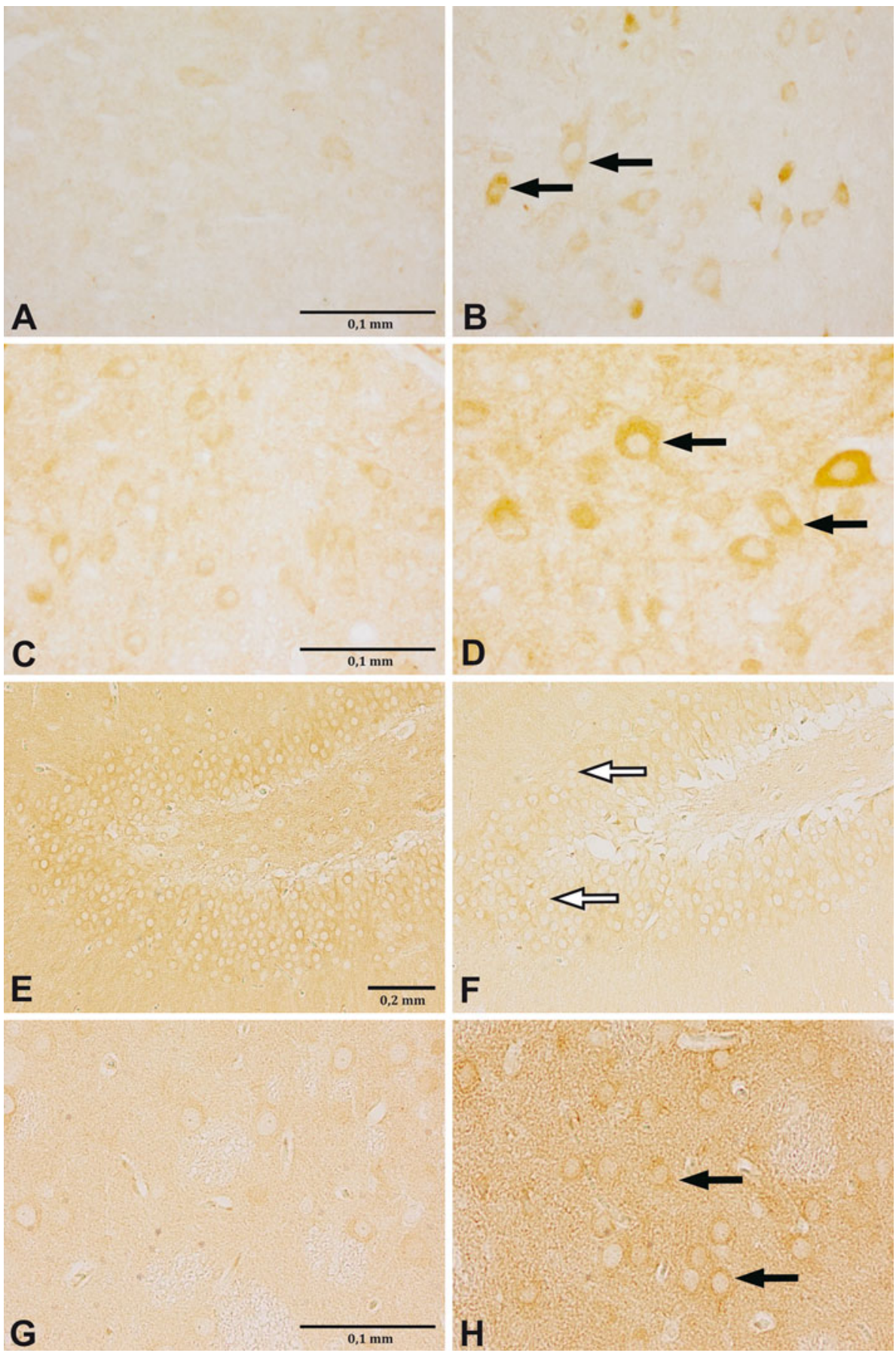

Table 1 Effect of postnatal THIM treatment on MOR density in the PAG area in 8-week old rats: lower doses of THIM

\begin{tabular}{|c|c|c|c|c|c|c|c|c|}
\hline \multirow[t]{2}{*}{$\mathrm{Hg}$ dose $(\mu \mathrm{g} / \mathrm{kg})$} & \multicolumn{4}{|c|}{ DMPAG } & \multicolumn{4}{|l|}{ LPAG } \\
\hline & $\mathrm{AV}-\mathrm{AF}$ & \pm SEM & $P$ & $\%$ CTRL & $\mathrm{AV}-\mathrm{AF}$ & \pm SEM & $P$ & $\%$ CTRL \\
\hline 0 & 4.39 & 1.79 & & 100 & 1.76 & 0.35 & & 100 \\
\hline 12 & 14.44 & 1.94 & n.s. & 328 & 4.19 & 1.16 & n.s. & 238 \\
\hline 240 & 21.36 & 4.47 & 0.007 & 485 & 8.29 & 2.73 & n.s. & 471 \\
\hline
\end{tabular}

$A V$-AF Average stained area fraction (\% of the area), \% CTRL percent of control value, $P$ significancy. Neonatal rats' exposure to THIM doses 12 and $240 \mu \mathrm{g} / \mathrm{kg}$ causes increases in MOR density in DMPAG and LPAG areas. Statistical analysis is described in the "Results" section 
Table 2 Effect of postnatal THIM treatment on MOR density in the PAG area in 20-week old rats: higher doses of THIM

\begin{tabular}{|c|c|c|c|c|c|c|c|c|}
\hline \multirow[t]{2}{*}{$\mathrm{Hg}$ dose $(\mu \mathrm{g} / \mathrm{kg})$} & \multicolumn{4}{|l|}{ DMPAG } & \multicolumn{4}{|l|}{ LPAG } \\
\hline & $\mathrm{AV}-\mathrm{AF}$ & \pm SEM & $P$ & $\%$ CTRL & AV-AF & \pm SEM & $P$ & $\%$ CTRL \\
\hline 0 & 0.95 & 0.208 & & 100 & 0.222 & 0.060 & & 100 \\
\hline 1,440 & 6.85 & 1.202 & $<0.001$ & 717 & 3.179 & 0.619 & $<0.001$ & 1,432 \\
\hline 3,000 & 4.47 & 0.656 & 0.009 & 468 & 3.432 & 0.533 & $<0.001$ & 1,546 \\
\hline
\end{tabular}

$A V-A F$ Average stained area fraction (\% of the area), $\%$ CTRL percent of control value, $P$ significancy. Neonatal rats' exposure to THIM doses 1,440 and 3,000 $\mu \mathrm{g} / \mathrm{kg}$ causes increases in MOR density in DMPAG and LPAG areas. Statistical analysis is described in the "Results" section

Table 3 Effect of postnatal THIM treatment on MOR density in the caudate putamen (CPU) and the dentate gyrus (DG) areas in 20-week old rats

\begin{tabular}{|c|c|c|c|c|c|c|c|c|}
\hline \multirow[t]{2}{*}{$\mathrm{Hg}$ dose $(\mu \mathrm{g} / \mathrm{kg})$} & \multicolumn{4}{|l|}{$\mathrm{CPU}$} & \multicolumn{4}{|l|}{ DG } \\
\hline & $\mathrm{AV}-\mathrm{AF}$ & \pm SEM & $P$ & $\%$ CTRL & AV-AF & \pm SEM & $P$ & $\%$ CTRL \\
\hline 0 & 3.583 & 0.456 & & 100 & 1.655 & 0.612 & & 100 \\
\hline 1,440 & 3.835 & 0.913 & n.s. & 107 & 1.117 & 0.444 & 0.02 & 67 \\
\hline 3,000 & 8.301 & 2.553 & 0.02 & 232 & 0.307 & 0.132 & 0.005 & 18 \\
\hline
\end{tabular}

$A V$-AF Average stained area fraction (\% of the area), \% CTRL percent of control value, $P$ significancy. Neonatal rats' exposure to THIM doses 1,440 and 3,000 $\mu \mathrm{g} / \mathrm{kg}$ causes increase in MOR density in the CPU, but decrease in DG area. Statistical analysis is described in the "Results" section

ANOVA revealed statistically significant effect of dose $[F(2,12)=14.235 ; P<0.001]$ and the post-hoc analysis confirmed such effect at both doses, 1,440 and 3,000 $\mu \mathrm{g} \mathrm{Hg} / \mathrm{kg}$ $(P<0.001)$. In the DMPAG, the increasing trend was observed up to dose $1,440 \mu \mathrm{g} \mathrm{Hg} / \mathrm{kg}$, where MOR density reached $717 \%$ of control, and in the LPAG - up to a dose of $3,000 \mu \mathrm{g} \mathrm{Hg} / \mathrm{kg}$, where it reached $1,546 \%$ of control value. These data clearly show that neonatal THIM treatment produces dose-dependent increases in MOR density in the PAG area. This effect is long lasting, as it persists until at least the postnatal week 20th. Very likely it is permanent.

At the dose $3,000 \mu \mathrm{g} \mathrm{Hg} / \mathrm{kg}$, THIM also augmented MOR density in the CPU. In contrast, the administration of THIM at both higher doses decreased MOR density in the DG (Table 3). This reduction was dose-dependent, reaching 67 and $18 \%$ of the control value at doses 1,440 and 3,000 $\mu \mathrm{g}$ $\mathrm{Hg} / \mathrm{kg}$, respectively. For the CPU area, one way ANOVA revealed statistically significant effect of dose $[F(2,6)=$ 6.948; $P<0.02$ ] and the post-hoc analysis confirmed such effect at dose $3,000 \mu \mathrm{g} \mathrm{Hg} / \mathrm{kg}(P=0.02)$. For the DG area, one way ANOVA revealed statistically significant effect of dose $[F(2,6)=6.948 ; P<0.02]$ and the post-hoc analysis confirmed such effect at doses $1,440 \mu \mathrm{g} \mathrm{Hg} / \mathrm{kg}(P<0.02)$ and $3,000 \mu \mathrm{g} \mathrm{Hg} / \mathrm{kg}(P=0.005)$.

In order to assess if the THIM-induced decline of MOR density in the DG was due to a potential loss of hippocampal neurons or synapses, we conducted a neuropathological examination of this brain region. Figure $2 \mathrm{~A}-\mathrm{C}$ illustrates examples of neuropathological changes in the dorsal hippocampus (Bregma -3.60) of rats, which at neonatal stage received four injections of THIM at doses 12 or $240 \mu \mathrm{g} \mathrm{Hg} /$ $\mathrm{kg}(N=5$ per group). Characteristic ischemic-like degeneration of neurons and dark neurons were observed in the granular layer of the DG area, CA1 and CA3 fields in THIMtreated rats. These pathological changes were more extensive in animals treated with higher doses of THIM. Neurons in the control group looked normal.

To evaluate possible changes in synaptic density, the hippocampi of experimental animals were examined for immunoreactivity to synaptophysin - the protein marker for presynaptic vesicles. Synaptophysin reaction was drastically diminished in tissues from THIM-injected rats (Fig. 2D-E), suggesting reduced synaptic content or decreased synaptophysin concentration in synaptic vesicles. In the hippocampus CA3 fields from animals treated with THIM dose $12 \mu \mathrm{g}$ $\mathrm{Hg} / \mathrm{kg}$, the synaptophysin reaction was reduced on average by $47 \%$ and in the tissues from rats treated with THIM dose $240 \mu \mathrm{g} \mathrm{Hg} / \mathrm{kg}$, it was reduced by $61 \%(N=5$ per experimental group). The one way ANOVA revealed a significant effect of $\mathrm{Hg}$ dose $[F(2,24)=12.323 ; P<0.001]$ and the post-hoc analysis confirmed such effect for THIM doses 12 and $240 \mu \mathrm{g} \mathrm{Hg} / \mathrm{kg}(P<0.05)$.

\section{Discussion}

The present study extends our earlier finding of persistent hypoalgesia, apparently mediated by endogenous opioids, in rats exposed to THIM during the early postnatal period [11]. We now show that neonatal THIM administration also 


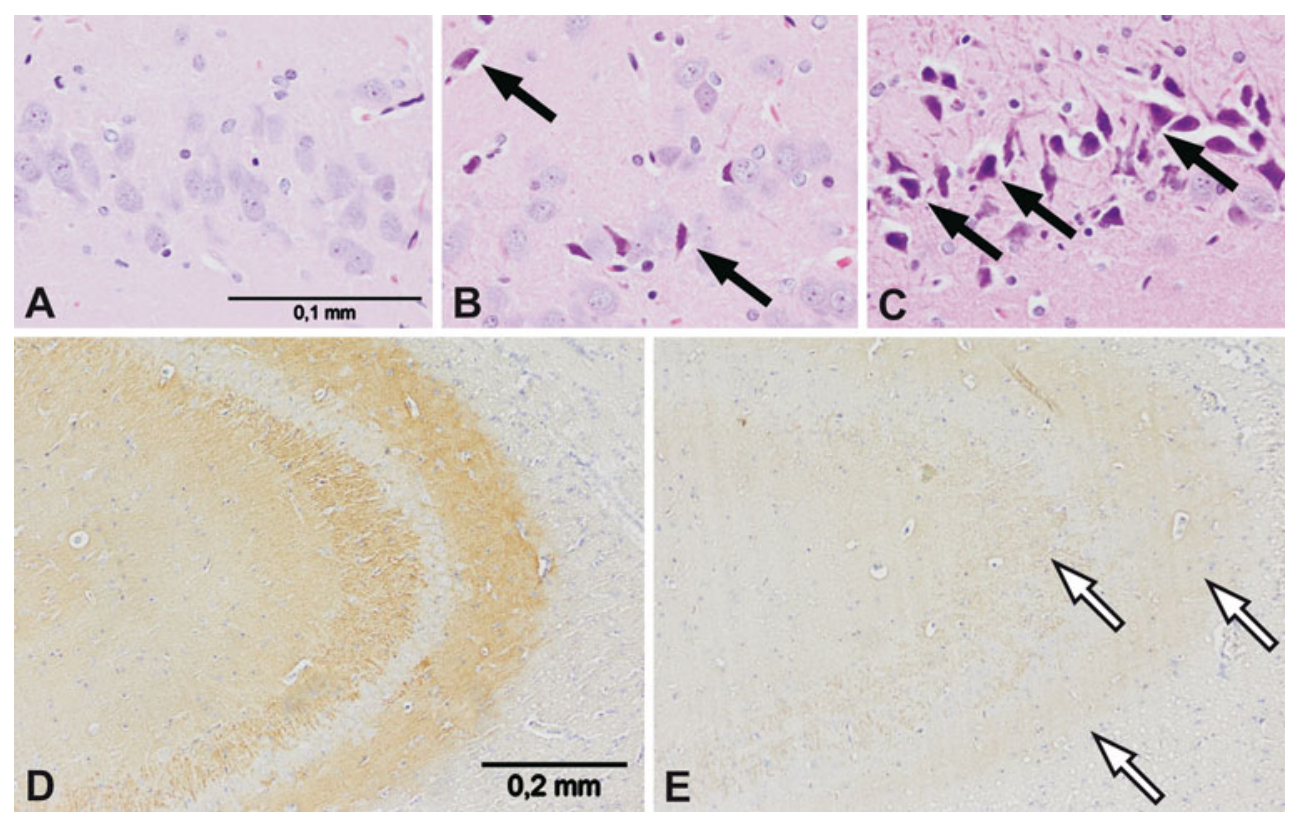

Fig. 2 Neuropathological changes in the hippocampi of neonatally THIM-treated rats, 8-week old. Images a-c show dark neurons and ischemic-like degeneration (marked with black arrows) of the hippocampal neurons in the dentate gyrus of THIM-treated rats. a Control group; b THIM dose $12 \mu \mathrm{g} \mathrm{Hg} / \mathrm{kg}$; c THIM dose $240 \mu \mathrm{g}$

changes densities of MORs in several brain regions. A marked THIM-induced, dose-dependent increase of MOR density was found in the PAG - the midbrain region associated with pain modulation [18-20]. The effect was clearly noticeable already at the lowest dose of THIM $(12 \mu \mathrm{g} \mathrm{Hg} /$ $\mathrm{kg}$ ), equivalent to those used in pediatric vaccines, although at this dose it did not reach statistical significance. However in behavioral tests, the same dose produced statistically significant hypoalgesia [11]. At higher doses of THIM, statistically significant increases of MOR density were observed in this brain region. Similar effect was noted in the CPU, though only at the highest dose of THIM. The opposite trend was seen in the DG, where THIM treatment led to a substantial reduction in MOR density.

Our finding of augmented MOR density in the PAG and CPU regions in adult rats, which were exposed to THIM in early postnatal life, resembles the study results of Zanoli et al. [12] in the brains of rats exposed to methylmercury in utero. The neurochemical/cellular mechanism(s) underlying these changes are not known at present; their elucidation requires further studies. Nonetheless, several possibilities are worth taking into consideration. In vitro, mercurials inhibit ligand binding to MOR [21] due to the formation of $\mathrm{Hg}$ adducts with the receptor's- $\mathrm{SH}$ groups, critical for its function [22-24]. It is possible that the THIM-induced increase in MOR density represents enduring, compensatory receptor upregulation, which resembles the effect of chronic treatment with opiate receptor antagonist [25]. Another potential mechanism may
$\mathrm{Hg} / \mathrm{kg}$; magnification $\times 400$. Images $\mathbf{d}-\mathbf{e}$ show diminished synaptophysin reaction (loss of synapses or synaptic marker protein) in the hippocampi of THIM-treated rats (marked with white arrows). d Control group; e THIM dose $240 \mu \mathrm{g} \mathrm{Hg} / \mathrm{kg}$; magnification $\times 200$

involve the activity of certain inflammatory cytokines, which can induce MOR gene expression in neuronal and immune cells [26], as production of these molecules is stimulated by THIM [27]. Moreover, since the second postnatal week, when our animals received THIM injections, coincides with rapid amplification of MORs in the rat brain [28, 29], it is possible that THIM interfered with this process by altering receptor gene expression through direct or indirect pathways [30, 31]. Other mechanisms of MORs' amplification cannot be excluded.

In the DG, unlike in the PAG area, neonatal THIM injections caused reduction in MOR density. It is not clear at present, why MORs in this brain region respond differently to mercurial exposure than those in the PAG or CPU. In other experiments, chronic rat treatment with an opiate receptor antagonist, led to up regulation of hippocampal MORs, analogous to that in the PAG and other brain regions [25], but seizures induced by pilocarpine resulted in decrease of MOR density in the DG [32]. Distinct response of MORs in the DG to THIM treatment may be due to different functional role of these receptors in the hippocampus than in other brain structures. While in most brain areas MORs are mostly postsynaptic and exert neuroinhibitory effects, a substantial proportion of hippocampal MORs are presynaptic, located on GABAergic interneurons, which are inhibited by activity of these receptors, exerting net excitatory actions [33].

The mechanism of THIM-induced decline of hippocampal MORs may be complex. It may be due to disrupted 
receptor ontogenesis, which is most active during the first two postnatal weeks in rats [29], due to functional receptors' down regulation, or loss of MORs containing neurons or synapses. The latter possibility is quite probable, as pathological examination of the hippocampi from THIMtreated rats revealed ischemic-like degenerating and dark neurons in the DG, accompanied by a striking reduction of synaptophysin content. Analogous loss of synaptophysin accompanied by inflammatory processes was induced in immature rats by exposure to lead, indicating neurotoxic/ neurodegenerative processes [34]. Because in rats the second postnatal week is a period of dynamic developmental changes in hippocampal synaptogenesis [35], the loss of synaptophysin in THIM-exposed animals may suggest disruption of this process, excessive synaptic pruning, or neuronal degeneration. The parallel down regulation or loss of hippocampal MORs and synaptophysin is consistent with the finding, that this protein regulates MOR trafficking and signaling [36]. Pathophysiological consequences of THIMinduced changes in the hippocampus are likely to be considerable, as opioids modulate many hippocampal functions including the development of neonatal neurotransmitter systems, neuronal excitability, learning, neurogenesis, neuronal survival, stress reactions and other functions [33, 37].

Alterations of MOR densities in the brains of THIMexposed animals are expected to have significant pathophysiological effects. Since the PAG is involved in pain regulation [18-20], an increase of MOR density in this region is likely to augment the activity of endogenous and exogenous opioids. Indeed we observed such an effect in THIM-treated rats in the form of hypoalgesia and amplified sensitivity to morphine [11]. These preclinical findings can be extrapolated, with caution, to certain clinical situations, particularly to a spectrum of neurodevelopmental disorders, where THIM is a suspected iatrogenic factor. It is possible that in the brains of susceptible infants, e.g. those with impaired capacity for metal elimination [38, 39] or with other biologic vulnerabilities, administration of THIM-containing vaccines may cause similar changes in MORs, as are seen in rats. This would alter sensitivity of such children to endogenous opioids. Such changes may contribute to dysfunctional opioid system in autistic individuals [40, 41] and may be responsible, at least in part, for their anecdotally reported impaired nociception and increased sensitivity to food-derived exomorphins (casomorphin and gliadomorphin). MORs upregulation in the PAG may as well affect other physiological functions such as heart rate, feeding, sleep and motor activity [19], which are often disturbed in autistics [42].

Our earlier pharmacokinetic study documented that $\mathrm{Hg}$ from i.m. THIM administration rapidly accumulates in the rat brain, with peak levels reached 4 days after the injection, and that it remains there for many weeks and possibly months [11]. The neurotoxic/pathological changes are probably initiated during a few days after injections of THIM, when its brain concentrations are the highest, but are likely to continue for months or be permanent, as documented by the results of our neuropathological and behavioral experiments, conducted many weeks after THIM administration. The persistent alterations of brain opioid systems ensuing from early life exposure to THIM is just one element of a plethora of neurodevelopmental pathologies induced by this mercurial in animals and humans [6-9, 11]. Its harmful effects are likely to be augmented by other vaccine adjuvants, such as aluminum, formaldehyde or antibiotics, and by various environmental toxins [31, 43, 44]. Particularly aluminum compounds, added to vaccines to augment their immunogenicity, have been shown to synergistically potentiate THIM's neurotoxicity [43]. Thus in the presence of other toxins or substances, which per se may be rather innocuous, even small doses of THIM in vaccines can lead to neurological injury in vulnerable children.

In conclusion, this study documents that parenteral administration of THIM to suckling rats at doses equivalent to those used in pediatric vaccines or higher produces lasting alterations of MORs in several brain regions and damage to neurons. If analogous changes occur in the brains of some children, they are likely to have profound neurological, physiological and behavioral consequences, which may be relevant for certain neurodevelopmental disorders. These data argue for removal of THIM from all infant vaccines.

Acknowledgments This publication is a part of ASTER project funded by the European Commission grant (MEXC-CT 2006-042371) and by the supplementary funding from the Ministry of Science and Higher Education of Poland, both to Maria Dorota Majewska.

Open Access This article is distributed under the terms of the Creative Commons Attribution Noncommercial License which permits any noncommercial use, distribution, and reproduction in any medium, provided the original author(s) and source are credited.

\section{References}

1. Qvarnström J, Lambertsson L, Havarinasab S, Hultman P, Frech W (2003) Determination of methylmercury, ethylmercury, and inorganic mercury in mouse tissues, following administration of thimerosal, by species-specific isotope dilution GC-inductively coupled plasma-MS. Anal Chem 75:4120-4124

2. Pichichero ME, Gentile A, Giglio N, Umido V, Clarkson T, Cernichiari E, Zareba G, Gotelli C, Gotelli M, Yan L, Treanor T (2008) Mercury levels in newborns and infants after receipt of thimerosal-containing vaccines. Pediatrics 121:208-214

3. Stajich GV, Lopez GP, Harry SW, Sexson WR (2000) Iatrogenic exposure to mercury after hepatitis B vaccination in preterm infants. J Pediatr 136:679-681

4. Burbacher WM, Grant KS, Mayfield DB, Gilbert SG, Rice DC (2005) Prenatal methylmercury exposure affects spatial vision in adult monkeys. Toxicol Appl Pharmacol 208:21-28 
5. Yel L, Brown LE, Su K, Gollapudi S, Gupta S (2005) Thimerosal induces neuronal cell apoptosis by causing cytochrome $\mathrm{c}$ and apoptosis-inducing factor release from mitochondria. Int $\mathrm{J}$ Mol Med 16:971-977

6. Hornig M, Chian D, Lipkin WI (2004) Neurotoxic effects of postnatal thimerosal are mouse strain dependent. Mol Psychiatry 9:833-845

7. Bernard S, Enayati A, Redwood L, Roger H, Binstock T (2001) Autism: a novel form of mercury poisoning. Med Hypotheses 56: 462-471

8. Geier MR, Geier DA (2003) Neurodevelopmental disorders after thimerosal-containing vaccines: a brief communication. Exp Biol Med 228:660-664

9. Mutter J, Naumann J, Schneider R, Walach H, Haley B (2005) Mercury and autism: accelerating evidence? Neuroendocrinol Lett 26:439-446

10. Young H, Geier D, Geier M (2008) Thimerosal exposure in infants and neurodevelopmental disorders: an assessment of computerized medical records in the vaccine safety datalink. J Neurol Sci 271:110-118

11. Olczak M, Duszczyk M, Mierzejewski P, Majewska MD (2009) Neonatal administration of a vaccine preservative, thimerosal, produces lasting impairment of nociception and apparent activation of opioid system in rats. Brain Res 1301:143-151

12. Zanoli P, Truzzi C, Veneri C, Brandoli C, Baraldi M (1997) Prenatal exposure to methylmercury during late gestation affects cerebral opiatergic system in rat offspring. Environ Res 74:48-53

13. Magos L, Brown AW, Sparrow S, Bailey E, Snowden RT, Skipp RS (1985) The comparative toxicology of ethyl- and methylmercury. Arch Toxicol 57:260-267

14. Herkenham M, Pert CB (1980) In vitro autoradiography of opiate receptors in rat brain suggests loci of "opiatergic" pathways. Proc Natl Acad Sci USA 77:5532-5536

15. Moskowitz AS, Goodman RR (1985) Autoradiographic distribution of mu1 and mu2 opioid binding in the mouse central nervous system. Brain Res 360:117-129

16. Paxinos G, Watson C (2007) The rat brain in stereotaxic coordinates. Academic Press, Oxford

17. Anderson BD, Nakamura T, Russell SJ, Peng KW (2004) High CD46 receptor density determines preferential killing of tumor cells by oncolytic measles virus. Cancer Res 64:4919-4926

18. Basbaum AI, Fields HL (1978) Endogenous pain control mechanisms: review and hypothesis. Ann Neurol 4:451-462

19. Mason P (2005) Ventromedial medulla: pain modulation and beyond. J Comp Neurol 493:2-8

20. Smith DJ, Perrotti JM, Crisp T, Cabral ME, Long JT, Scalzitti JM (1988) The mu opiate receptor is responsible for descending pain inhibition originating in the periaqueductal gray region of the rat brain. Eur J Pharmacol 156:47-54

21. Tejwani GA, Hanissian SH (1990) Modulation of mu, delta and kappa opioid receptors in rat brain by metal ions and histidine. Neuropharmacology 29:445-452

22. Deng HB, Guang W, Wang JB (2000) Selected cysteine residues in transmembrane domains of mu-opioid receptor are critical for effects of sulfhydryl reagents. J Pharmacol Exp Ther 293: $113-120$

23. Trümpler S, Lohmann W, Meermann B, Buscher W, Sperling M, Karst U (2009) Interaction of thimerosal with proteins-ethylmercury adduct formation of human serum albumin and $\beta$-lactoglobulin A. Metallomics 1:87-91

24. Ofri D, Simon EJ (1992) Sulfhydryl groups on opioid receptors revisited, evidence for two sulfhydryl groups at or near the active site of the mu opioid receptor. Receptor 2:109-119
25. Tempel A, Gardner EL, Zukin RS (1984) Visualization of opiate receptor upregulation by light microscopy autoradiography. Proc Natl Acad Sci USA 81:3893-3897

26. Börner C, Kraus J, Schröder H, Ammer H, Höllt V (2004) Transcriptional regulation of the human mu-opioid receptor gene by interleukin-6. Mol Pharmacol 66:1719-1726

27. Havarinasab S, Häggqvist B, Björn E, Pollard JM, Hultman $P$ (2005) Immunosuppressive and autoimmune effects of thimerosal in mice. Toxicol Appl Pharmacol 204:109-121

28. Auguy-Valette A, Cros J, Gouarderes C, Gout R, Pontonnier G (1978) Morphine analgesia and cerebral opiate receptors: a developmental study. Br J Pharmacol 63:303-308

29. Unnerstall JR, Molliver ME, Kuhar MJ, Palacios JM (1983) Ontogeny of opiate binding sites in the hippocampus, olfactory bulb and other regions of the rat forebrain by autoradiographic methods. Brain Res 283:157-169

30. Glover CN, Zheng D, Jayashankar S, Sales GD, Hogstrand C, Lundebye AK (2009) Methylmercury speciation influences brain gene expression and behavior in gestationally-exposed mice pups. Toxicol Sci 110:389-400

31. Waly M, Olteanu H, Banerjee R, Choi SW, Mason JB, Parker BS, Sukumar S, Shim S, Sharma A, Benzecry JM, Power-Charnitsky VA, Deth RC (2004) Activation of methionine synthase by insulin-like growth factor-1 and dopamine: a target for neurodevelopmental toxins and thimerosal. Mol Psychiatry 4:358-370

32. Bausch SB, Chavkin C (1997) Changes in hippocampal circuitry after pilocarpine-induced seizures as revealed by opioid receptor distribution and activation. J Neurosci 17:477-492

33. Drake CT, Chavkin C, Milner TA (2007) Opioid systems in the dentate gyrus. Prog Brain Res 163:245-263

34. Struzynska L, Dabrowska-Bouta B, Koza K, Sulkowski G (2007) Inflammation-like glial response in lead-exposed immature rat brain. Toxicol Sci 95:156-162

35. Moryś J, Berdel B, Kowiański P, Dziewiatkowski J (1998) The pattern of synaptophysin changes during the maturation of the amygdaloid body and hippocampal hilus in the rat. Folia Neuropathol 36:15-23

36. Liang YJ, Wu DF, Yang LQ, Höllt V, Koch T (2007) Interaction of the mu-opioid receptor with synaptophysin influences receptor trafficking and signaling. Mol Pharmacol 71:123-131

37. Tegeder I, Geisslinger G (2004) Opioids as modulators of cell death and survival-unraveling mechanisms and revealing new indications. Pharmacol Rev 56:351-369

38. Holmes AS, Blaxill MF, Haley BE (2003) Reduced levels of mercury in first baby haircuts of autistic children. Int J Toxicol 22:277-285

39. Majewska MD, Urbanowicz E, Rok-Bujko P, Namyslowska I, Mierzejewski P (2010) Age-dependent lower or higher levels of hair mercury in autistic children than in healthy controls. Acta Neurobiol Exp (Wars) 70:196-208

40. Sandman CA (1988) Beta-endorphin disregulation in autistic and self-injurious behavior: a neurodevelopmental hypothesis. Synapse 2:193-199

41. Sandyk R, Gillman M (1986) Infantile autism: a dysfunction of the opioids? Med. Hypotheses 19:41-45

42. Ming X, Julu PO, Brimacombe M, Connor S, Daniels ML (2005) Reduced cardiac parasympathetic activity in children with autism. Brain Dev 27:509-516

43. Haley BE (2005) Mercury toxicity: genetic susceptibility and synergistic effects. Med Veritas 2:535-542

44. Blaylock RL (2009) A possible central mechanism in autism spectrum disorders, part 3: the role of excitotoxin food additives and the synergistic effects of other environmental toxins. Altern Ther Health Med 15:56-60 